\title{
Microsatellite instability and hMLH1 and hMSH2 expression in renal tumors
}

\author{
GIUSEPPE ALTAVILLA ${ }^{1}$, MATTEO FASSAN ${ }^{1}$, GRAZIELLA BUSATTO ${ }^{2}$, \\ MARTINA ORSOLAN $^{2}$ and LUCIANO GIACOMELLI ${ }^{3}$
}

\author{
${ }^{1}$ Department of Diagnostic Medical Sciences and Special Therapies, Pathology Unit, University of Padova; ${ }^{2}$ Department \\ of Pathology, ULSS15, Cittadella Hospital; ${ }^{3}$ Azienda Ospedaliera di Padova, Pathology Unit, Padova, Italy
}

Received April 6, 2010; Accepted June 15, 2010

DOI: $10.3892 /$ or_00000938

\begin{abstract}
Defects in the function of mismatch repair (MMR) genes result in genetic instability, a common feature of malignant progression. This study was conducted to determine the frequency of genetic instability [defined as microsatellite instability (MSI)] and to evaluate the sensitivity/specificity of immunohistochemistry in predicting the deficiency in $M M R$ genes in renal cortical tumors. A total of 51 surgically-resected renal tumors (27 clear cell, 10 papillary, 5 chromophobe carcinomas and 9 oncocytomas) were studied. We also analyzed the correlation with clinicopathological parameters, the MSI status (assessed by using 5 microsatellite markers: D2S123, D11S904, D3S1621, D3S1683 and BAT26), and the immunohistochemical expression of 2 major $M M R$ genes [the human mutL homolog 1 ( $h M L H 1)$ and the human mutS homolog 2 (hMSH2)]. Sixteen cases (31.4\%) showed MSI: Three $(5.9 \%)$ demonstrated a high level of MSI, 11 (21.6\%) demonstrated a low level of MSI, $2(3.9 \%)$ presented with a loss of heterozygosity, and the remaining 35 (68.6\%) exhibited microsatellite stability. The loss of hMLH1 and hMSH2 immunohistochemical expressions was observed in 5/51 $(9.8 \%)$ and $9 / 51(17.6 \%)$ cases, respectively. The complete absence of both hMLH1 and hMSH2 immunohistochemical expressions was observed only in the 3 cases with a high level of MSI. This study showed that defects in MMR genes
\end{abstract}

Correspondence to: Professor Giuseppe Altavilla, Department of Diagnostic Medical Sciences and Special Therapies, University of Padova, Via A. Gabelli 61, 35100 Padova, Italy

E-mail: giuseppe.altavilla@unipd.it

Abbreviations: MSI, microsatellite instability; MSI-H, microsatellite instability-high; MSI-L, microsatellite instability-low; MSS, microsatellite stability; MMR, mismatch repair; $\mathrm{LOH}$, loss of heterozygosity; CLEAR, clear cell carcinoma; PAP, papillary carcinoma; CHR, chromophobe carcinoma; ONC, oncocytoma

Key words: renal cell carcinoma, microsatellite analysis, microsatellite instability are involved in renal carcinogenesis and correlate with the occurrence of MSI.

\section{Introduction}

Renal tumors represent $4 \%$ of all adult malignancies in the United States, accounting for $<57,000$ newly diagnosed cases and $\sim 13,000$ deaths each year (1). As a histopathologically heterogeneous entity, most sporadic tumors $(\sim 80 \%)$ are classified as clear cell (or non-papillary) tumors, with $12 \%$ of non-clear cell tumors predominantly classed as oncocytomas (ONCs) and 5\% as chromophobe carcinomas (CHRs) (2).

The histopathology of these neoplasms has been correlated with distinctively different genetic changes, indicating that unrelated molecular mechanisms underlie the development of each type of tumor (3-6). The most frequent genetic alterations implicated in renal cell carcinomas, particularly in the clear cell type, are located on the short arm of chromosome 3, where the $V H L$ tumor suppressor gene is also located (i.e. 3p26-p25) (3,7).

Mismatch repair $(M M R)$ genes are involved in the recognition and repair of the nucleotide mismatch during DNA replication (8). Alterations in the expression or sequence of $M M R$ genes have been shown to result in genetic instability, a phenomenon also known as microsatellite instability (MSI) (8-12). Microsatellite sequences are highly unstable in tumor cells with defective DNA mismatch repair. Therefore, microsatellites are markers of mutator phenotypes and a measure for defects in the DNA mismatch repair pathway. MSI has been characterized by the variations in the size of simplesequence nucleotide repeats in tumor DNA compared with normal DNA of the same individual (8).

Previous studies have demonstrated alterations in $M M R$ genes [such as the human mutL homolog 1 (hMLH1) and the human mutS homolog 2 (hMSH2)] and the presence of MSI in human cancers, as well as in renal tumors (13-31). However, data on the incidence of MSI in renal cortical cancers is conflicting and the role of the MMR genes in these malignancies is still largely unknown.

In order to determine the contribution of the defects in $M M R$ genes in renal cortical carcinogenesis, we retrospectively examined a series of 51 renal tumors for MSI and MMR protein expression and correlated these findings with clinicopathological features. 
Table I. Microsatellites used in this study.

\begin{tabular}{|c|c|c|c|c|}
\hline Name & Location & Primers & $\mathrm{Tm}$ & Size (bp) \\
\hline D2S123 & $2 \mathrm{p} 16$ & $\begin{array}{l}\text { AAA CAG GAT GCC TGC CTT TA } \\
\text { GGA CTT TCC ACC TAT GGG AC }\end{array}$ & 60 & $197-227$ \\
\hline D11S904 & $11 \mathrm{p} 14 / 13$ & $\begin{array}{c}\text { ATG ACA AGC AAT CCT TGA GC } \\
\text { CTG TGT TAT ATC CCT AAA GTG GTG A }\end{array}$ & 58 & $185-201$ \\
\hline D3S1621 & $3 p 14 / 15$ & $\begin{array}{l}\text { CCT CAC TAG TCC TGG AAT TG } \\
\text { CCA AGG AAG GGT TTT ACT TA }\end{array}$ & 56 & 140 \\
\hline D3S1283 & $3 \mathrm{p} 24.2 / 22$ & $\begin{array}{l}\text { GGC AGT ACC ACC TGT AGA AAT G } \\
\text { GAG TAA CAG AGG CAT CGT GTA TTC }\end{array}$ & 60 & $150-160$ \\
\hline BAT26 & $2 p$ & $\begin{array}{c}\text { TGA CTA CTT TTG ACT TCA GCC } \\
\text { AAC CAT CCA ACA TTT TTA ACC C }\end{array}$ & 58 & $80-100$ \\
\hline
\end{tabular}

\section{Materials and methods}

Patients and tissue samples. Matched pairs of formalin-fixed, paraffin-embedded normal and tumor tissue samples of 51 patients with renal tumors [27 clear cell (CLEARs), 10 papillary carcinomas (PAPs), 5 CHRs and 9 renal ONCs] were collected from the 2000 to 2003 the archives of the Department of Surgical Pathology of the Cittadella Hospital (U.L.S.S. 15, 'Alta Padovana', Cittadella, Padova, Italy). None of these patients were known to have von HippelLindau syndrome. The samples were used with the approval of the Institutional Review Board. Informed consent was obtained from all the patients involved in the study.

The gross surgical specimens were all examined according to a standardized protocol. Gross serial sections were obtained from the whole resected kidney, enabling tissue samples to be collected from both cancer and normal renal parenchyma. The tissue samples were routinely processed for histological examination. Serial sections (4-6 $\mu \mathrm{m}$ thick) were obtained from paraffin blocks and stained with H\&E or used for immunophenotyping. All the tumors were histologically re-evaluated according to the WHO classification (2) and staged according to the AJCC Staging and the TNM System (32).

Microdissection procedures and DNA extraction. Four consecutive $10-\mu \mathrm{m}$ thick sections were obtained for DNA extraction. The tumor tissues were manually (i.e. scalpel blade-assisted) microdissected from adjacent normal tissue to ensure that each tumor sample contained at least $70 \%$ neoplastic cells. Normal renal tissue from each case was microdissected by the same methods as the control. The material dissected was collected in Eppendorf vials and processed for DNA extraction, as previously described (32).

Analysis of MSI. Microsatellite instability was studied using 5 markers (D2S123, D11S904, D3S1621, D3S1683 and BAT26; Table I) according to the Bethesda panel proposed by Bocker et al (33). Extracted DNA (5 $\mu 1)$ ( 20 ng) were used in a $50 \mu 1 \mathrm{PCR}$ reaction which contained $10 \mathrm{X}$ buffer,
$\mathrm{MgCl}_{2}(1.5 \mathrm{mM})$, dNTPS $(200 \mu \mathrm{M})$, primers $(5 \mu \mathrm{M})$ and $\mathrm{dH}_{2} \mathrm{O}$. The optimal PCR cycle number for each chromosomal locus was selected to avoid the formation of multiple artifactual bands (Table I). The PCR products were analyzed on a $10-12 \%$ non-denaturing polyacrylamide gel and stained by Silver stain (Bio-Rad, San Diego, CA, USA). MSI was defined as the presence of additional bands in the PCRamplified product derived from neoplastic lesions in comparison to non-neoplastic tissues from the same patient. Tumors exhibiting MSI in 2 or more markers were defined as MSI-high (MSI-H). Tumors showing instability in only 1 marker were defined as MSI-low (MSI-L). The loss of 1 allele in a patient with a heterozygous genotype was interpreted as the loss of heterozygosity $(\mathrm{LOH})$. Tumors in which no marker exhibited MSI were considered to exhibit microsatellite stability (MSS). Samples positive for MSI or LOH were analyzed twice with a new PCR and electrophoresis to confirm the alteration.

Immunohistochemical analysis. In all the cases, immunohistochemical staining was performed automatically (Ventana Benchmark XT system; Touchstone, AZ, USA) for hMLH1 (clone 14, 1:50; Zymed, San Francisco, CA, USA) and hMSH2 (clone Ab-2, 1:100; Oncogene, La Jolla, CA, USA) according to the manufacturer's instructions. The sections were lightly counterstained with hematoxylin. The appropriate positive and negative controls were run concurrently. Immunohistochemical expression was scored by 1 pathologist (G.A.) with no knowledge of the patients' clinical history. The normal staining pattern of both hMLH1 and hMSH2 was nuclear. Infiltrating lymphocytes as well as stromal cells served as the internal positive controls. The cases were dichotomized as positive [positive staining of at least $10 \%$ of the tumor cell nuclei in almost 6 high-power microscopic fields (x400), corresponding to 1,000 observed cells] and negative $(\leq 10 \%)$.

Statistical analysis. The relationship of hMLH1 or hMSH2 immunostaining with MSI occurrence was calculated. The significance of the associations between the groups was 
Table II. Clinicopathological features, MSI status, and immunohistochemical results in 51 renal cell tumors.

\begin{tabular}{|c|c|c|c|c|c|c|c|c|c|c|c|}
\hline \multirow[t]{2}{*}{ No. } & \multirow[t]{2}{*}{ Gender } & \multirow[t]{2}{*}{ Age } & \multirow[t]{2}{*}{ Histology } & \multirow[t]{2}{*}{ D2S123 } & \multirow[t]{2}{*}{ D11S904 } & \multirow[t]{2}{*}{ D3S1621 } & \multirow[t]{2}{*}{ D3S1283 } & \multirow[t]{2}{*}{ BAT26 } & \multirow[t]{2}{*}{ MSI status } & \multicolumn{2}{|c|}{ IHC expression } \\
\hline & & & & & & & & & & hMLH1 & hMSH2 \\
\hline 1 & M & 50 & CLEAR & - & - & - & - & - & MSS & + & + \\
\hline 2 & $\mathrm{~F}$ & 67 & CLEAR & - & - & - & - & - & MSS & + & + \\
\hline 3 & M & 69 & CLEAR & - & - & - & - & - & MSS & + & + \\
\hline 4 & M & 67 & CLEAR & - & - & - & - & - & MSS & + & + \\
\hline 5 & M & 58 & CLEAR & - & + & - & - & - & MSI-L & - & + \\
\hline 6 & $\mathrm{~F}$ & 40 & CLEAR & - & - & - & - & - & MSS & + & + \\
\hline 7 & M & 47 & CLEAR & - & - & - & - & - & MSS & + & + \\
\hline 8 & $\mathrm{~F}$ & 59 & CLEAR & - & + & - & - & - & MSI-L & + & + \\
\hline 9 & $\mathrm{~F}$ & 73 & CLEAR & - & - & - & - & - & MSS & + & + \\
\hline 10 & M & 55 & CLEAR & - & - & - & - & - & MSS & + & + \\
\hline 11 & M & 72 & CLEAR & - & - & - & - & - & MSS & + & + \\
\hline 12 & M & 67 & CLEAR & + & - & - & - & - & MSI-L & + & - \\
\hline 13 & $\mathrm{~F}$ & 83 & CLEAR & - & - & - & - & - & MSS & + & + \\
\hline 14 & M & 51 & CLEAR & + & + & - & - & + & MSI-H & - & - \\
\hline 15 & $\mathrm{~F}$ & 74 & CLEAR & - & - & - & - & - & MSS & + & + \\
\hline 16 & $\mathrm{~F}$ & 58 & CLEAR & - & - & - & $\mathrm{LOH}$ & - & $\mathrm{LOH}$ & + & - \\
\hline 17 & $\mathrm{~F}$ & 71 & CLEAR & - & - & - & - & - & MSS & + & + \\
\hline 18 & $\mathrm{~F}$ & 74 & CLEAR & + & - & - & - & - & MSI-L & + & - \\
\hline 19 & M & 50 & CLEAR & - & - & - & - & - & MSS & + & + \\
\hline 20 & $\mathrm{~F}$ & 80 & CLEAR & - & - & - & - & - & MSS & + & + \\
\hline 21 & M & 72 & CLEAR & - & - & - & - & - & MSS & + & + \\
\hline 22 & M & 34 & CLEAR & - & - & - & - & - & MSS & + & + \\
\hline 23 & M & 52 & CLEAR & - & - & + & - & - & MSI-L & + & - \\
\hline 24 & M & 66 & CLEAR & - & - & - & - & - & MSS & + & + \\
\hline 25 & M & 55 & CLEAR & - & - & - & - & - & MSS & + & + \\
\hline 26 & $\mathrm{~F}$ & 75 & CLEAR & - & - & - & - & - & MSS & + & + \\
\hline 27 & M & 75 & CLEAR & - & - & - & - & - & MSS & + & + \\
\hline \multicolumn{2}{|c|}{ Total CLEAR } & & & $3 / 24$ & $3 / 24$ & $1 / 26$ & $1 / 26 \mathrm{LOH}$ & $1 / 26$ & & $2 / 25$ & $5 / 22$ \\
\hline 28 & M & 70 & PAP & - & - & - & - & - & MSS & + & + \\
\hline 29 & $\mathrm{~F}$ & 76 & PAP & - & - & - & - & - & MSS & + & + \\
\hline 30 & M & 73 & PAP & + & + & - & - & - & MSI-H & - & - \\
\hline 31 & M & 56 & PAP & + & + & + & - & - & MSI-H & - & - \\
\hline 32 & M & 76 & PAP & - & - & - & + & - & MSI-L & + & + \\
\hline 33 & M & 65 & PAP & - & - & - & - & - & MSS & + & + \\
\hline 34 & M & 55 & PAP & - & - & - & - & - & MSS & + & + \\
\hline 35 & M & 70 & PAP & - & - & - & - & - & MSS & + & + \\
\hline 36 & M & 22 & PAP & - & - & + & - & - & MSI-L & + & - \\
\hline 37 & M & 59 & PAP & - & - & - & - & - & MSS & + & + \\
\hline \multicolumn{2}{|c|}{ Total PAP } & & & $2 / 8$ & $2 / 8$ & $2 / 8$ & $1 / 9$ & $0 / 10$ & & $2 / 8$ & $3 / 7$ \\
\hline 38 & M & 65 & CHR & - & - & - & - & - & MSS & + & + \\
\hline 39 & M & 70 & CHR & - & - & - & - & - & MSS & - & + \\
\hline 40 & $\mathrm{~F}$ & 47 & CHR & - & - & - & - & - & MSS & + & + \\
\hline 41 & M & 68 & CHR & - & - & - & - & - & MSS & + & + \\
\hline 42 & M & 48 & CHR & - & - & + & - & - & MSI-L & + & + \\
\hline \multicolumn{2}{|c|}{ Total CHR } & & & $0 / 5$ & $0 / 5$ & $1 / 4$ & $0 / 5$ & $0 / 5$ & & $1 / 4$ & $0 / 5$ \\
\hline 43 & $\mathrm{~F}$ & 59 & ONC & - & - & - & - & - & MSS & + & + \\
\hline 44 & M & 72 & ONC & - & - & - & $\mathrm{LOH}$ & - & $\mathrm{LOH}$ & + & + \\
\hline
\end{tabular}


Table II. Continued.

\begin{tabular}{|c|c|c|c|c|c|c|c|c|c|c|c|}
\hline \multirow[t]{2}{*}{ No. } & \multirow[t]{2}{*}{ Gender } & \multirow[t]{2}{*}{ Age } & \multirow[t]{2}{*}{ Histology } & \multirow[t]{2}{*}{ D2S123 } & \multirow[t]{2}{*}{ D11S904 } & \multirow[t]{2}{*}{ D3S1621 } & \multirow[t]{2}{*}{ D3S1283 } & \multirow[t]{2}{*}{ BAT26 } & \multirow[t]{2}{*}{ MSI status } & \multicolumn{2}{|c|}{ IHC expression } \\
\hline & & & & & & & & & & hMLH1 & $\mathrm{hMSH} 2$ \\
\hline 45 & M & 78 & ONC & - & - & - & - & - & MSS & + & + \\
\hline 46 & $\mathrm{~F}$ & 61 & ONC & - & - & - & - & - & MSS & + & + \\
\hline 47 & M & 67 & ONC & - & - & - & - & - & MSS & + & + \\
\hline 48 & M & 70 & ONC & - & - & + & - & - & MSI-L & + & + \\
\hline 49 & M & 68 & ONC & + & - & - & - & - & MSI-L & + & + \\
\hline 50 & $\mathrm{~F}$ & 68 & ONC & - & - & - & - & - & MSS & + & + \\
\hline 51 & M & 62 & ONC & - & - & - & - & + & MSI-L & + & - \\
\hline \multicolumn{2}{|c|}{ Total ONC } & & & $1 / 8$ & $0 / 9$ & $1 / 8$ & $1 / 8 \mathrm{LOH}$ & $1 / 8$ & & $0 / 9$ & $1 / 8$ \\
\hline \multicolumn{2}{|c|}{ Total } & & & $6 / 45$ & $5 / 46$ & $5 / 46$ & $3 / 48$ & $2 / 49$ & & $5 / 46$ & $9 / 42$ \\
\hline
\end{tabular}

CLEAR, clear cell carcinoma; PAP, papillary carcinoma; CHR, chromophobe carcinoma; ONC, oncocytoma; MSI, microsatellite instability; MSI-H, MSI-high; MSI-L, MSI-low; MSS, microsatellite stability; LOH, loss of heterozygosity.

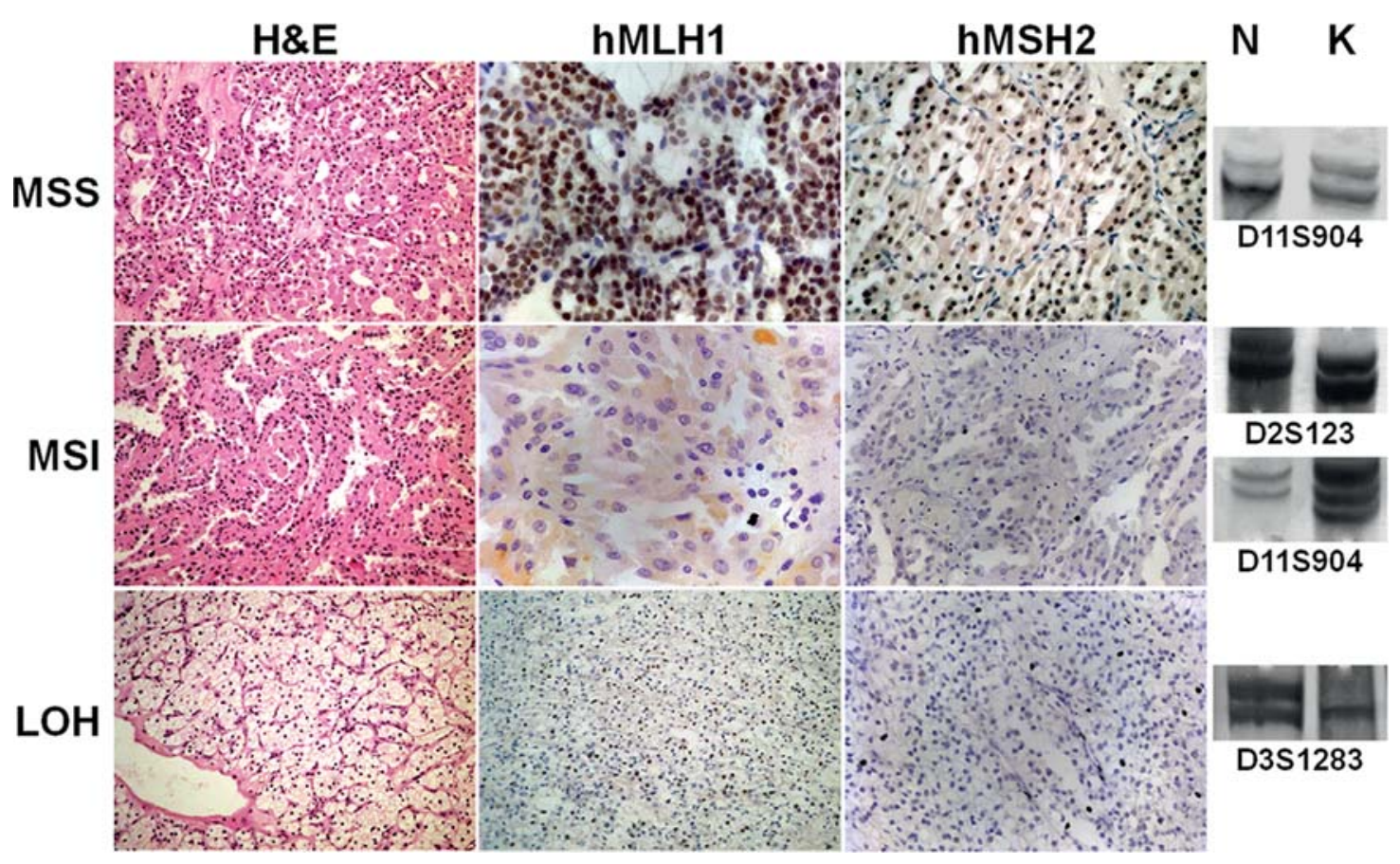

Figure 1. Representative examples of H\&E staining, hMLH1 and hMSH2 immunostains and MSI status of a case of MSS (case no. 46; ONC, hMLH1- and hMSH2-positive), a case of MSI (case no. 30; PAP, hMLH-1 and hMSH2-negative) and a case of LOH (case no. 16; CLEAR, hMLH-positive and with <10\% cell nuclei-positive for hMSH2). Original magnifications, $\mathrm{x} 200$ and $\mathrm{x} 400$.

analyzed using the Spearman's rho, Mann-Whitney and Fisher's exact tests. The values were considered significantly different when the p-value was $<0.05$. The statistical analysis was performed by one of the authors (L.G.) using STATA software (Stata Corporation, College Station, Texas, USA).

\section{Results}

The age of the patients ranged from 22 to 83 years, with a mean age of $63.1 \pm 12.2$ years. There were 35 males and 16 females (Table II).
Among the 51 renal tumors analyzed, 16 (31.4\%) showed MSI. In particular, 3 (5.9\%) were MSI-H, 11 (21.6\%) were MSI-L, 2 (3.9\%) cases presented with $\mathrm{LOH}$ and the remaining $35(68.6 \%)$ were MSS (Table II). No case of MSI-H was observed in the ONCs. The 5 markers used to detect MSI-H tumors had the following sensitivities: D2S123 (3 of 3), D11S904 (3 of 3), D3S1621 (1 of 3), D3S1683 (0 of 3) and BAT 26 ( 1 of 3). Representative examples of MSS and MSI tumors are shown in Fig. 1.

hMLH1 and hMSH2 immunoreactions were observed in $46 / 51(90.2 \%)$ and $42 / 51(82.4 \%)$ cases, respectively. The 
immunoreactivity of the 2 MMR proteins was predominantly localized in the cell nuclei. In the normal kidney samples, hMLH1 and hMSH2 were always expressed.

Eleven tumors (21.6\%) showed MMR IHC defects. The expression of hMLH1 and hMSH2 was inversely correlated with the incidence of MSI $(\mathrm{p}<0.001)$ : Of the 16 cases presenting with MSI, 4 cases did not show any immunoreactions for hMLH1 and 9 for hMSH2. Moreover, all the MSI-H cases lacked both the expresson of the MMR proteins by IHC. Only 1 of the 35 (2.9\%; no. 39) MSS-cases showed MMR IHC defects. The hMSH2 expression showed a higher sensitivity ( 1.000 vs 0.800$)$ and specificity (0.833 vs. 0.739$)$ than the hMLH1 expression in identifying MSI positive cases.

The statistical analysis of age, gender, tumor size, Fuhrman nuclear grading, TNM and UICC classifications disclosed no significant differences or trends between the cases with or without MSI or MMR IHC expression.

\section{Discussion}

Renal cortical tumors consist of a heterogeneous tumor group which is characterized by complex cytogenetic and molecular genetic abnormalities $(3,14)$. Accurate pathological classification is important, as different morphological tumor subtypes require specific therapeutic management due to markedly different prognoses and responses to therapy.

Microsatellite instability (MSI) is commonly seen in tumors associated with the hereditary non-polyposis colorectal cancer syndrome (HNPCC or Lynch syndrome II) and is mainly caused by defects in the DNA mismatch repair system (3).

MSI analysis is considered to be a promising technique for the investigation of somatic changes that occur during tumor progression and has become an important tool in renal tumor molecular pathology $(14,23)$. MSI analysis has previously been used: i) to determine the genetic alterations involved in different renal tumor histotypes $(19,28)$, ii) to study the possible inactivation of one or more tumor suppressor genes in renal cancer samples (25), and iii) to investigate the clonal origin of multifocal renal cell carcinomas $(21,22)$.

Furthermore, chromosome 3p MSI determined on plasma DNA has been proposed as a new diagnostic potential molecular tumor marker in patients with clear cell renal carcinoma $(18,29)$. However, the role and incidence of MSI in renal cell cancers is a matter of great controversy.

A number of prior studies have evaluated MSI in renal tumors $(13,15,17,24,26,27)$. However, there is remarkable and sometimes conflicting variability in terms of the type and number of loci studied, the criteria used for defining MSI, and the histological subtypes of renal cancer analyzed. Therefore, in our study, we addressed some of these deficiencies by examining a relatively sizeable series of tumors obtained from a single institution with stable fixation and processing methods.

As previously observed $(13,15,17,19,24,26,27)$, we found the relatively frequent incidence of MSI in malignant and relatively benign (ONCs) renal cortical neoplasms, without reasonable differences in the frequencies among the different tumor histotypes. These data confirm that genetic instability plays an important role in renal cortical carcinogenesis and this suggests that larger microsatellite panels should be used in the detection of histotype-specific genetic alterations.

A strong correlation has been demonstrated between alterations in the expression of the $M M R$ genes and the presence of MSI. Such MMR defects could be caused either by a germline $M M R$ gene mutation, or by somatic $M M R$ gene inactivation, most commonly through epigenetic silencing via the methylation of the gene promoter. Therefore, it has been hypothesized that the immunohistochemical analysis of the MMR proteins could offer an alternative method for assessing MSI status (34). Moreover, the deficiency in the $M M R$ genes could have important biological and clinical consequences such as chemoresistance and prognostic changes $(23,31)$.

The two key members of the MMR system are the hMLH1 and the hMSH2, as the other mutL homologues (PMS1 and PMS2) as well as the mutS homologues (hMSH3 and hMSH6), have been reported to be less stable in the absence of the first member of their lineage (35). The $h M L H 1$ gene is located at chromosome 3 p21, a region frequently involved in deletions and translocations in renal tumors (especially in the clear cell histotype) $(14,15)$, whereas the $h M S H 2$ gene is located at chromosome $2 \mathrm{p} 21$, close to microsatellite D2S123, which we found to be altered in $6(11.8 \%)$ of the analyzed cases.

$M M R$ gene mutations have been demonstrated in renal cancer samples and in renal cancer-derived cell lines $(14,16,17,23,31)$. In our study, the $h M L H 1$ and $h M S H 2$ expression was lost in all the three tumors with MSI-H, showing a high specificity and thus further confirming, that the loss of the MMR genes is involved in the renal cortical malignant transformation. Furthermore, the defect in the MMR proteins was observed in only 1 microsatellite-stable case (no. 39), suggesting that MMR immunohistochemical analysis has a high sensitivity in identifying MSI in renal tumors.

In conclusion, our data confirmed that genetic instability is a detectable phenomenon in human renal cancers and that it could be associated with the development of the disease. Further studies using a larger series of tumors are required in order to investigate the role of the MMR system and its possible prognostic impact in renal cortical tumors.

\section{Acknowledgements}

This study was supported by grants from the Italian 'Ministero dell'Istruzione, dell'Università e della Ricerca (MIUR)'.

\section{References}

1. Jemal A, Siegel R, Ward E, Hao Y, Xu J and Thun MJ: Cancer Statistics, 2009. CA Cancer J Clin 59: 225-249, 2009.

2. Eble JN, Sauter G, Epstein JI and Sesterhenn IA: World Health Organization Classification of Tumours. Pathology and Genetics of Tumours of the Urinary System and Male Genital Organs. IARC Press, Lyon, 2004.

3. Kovacs G: Molecular differential pathology of renal cell tumours. Histopathology 22: 1-8, 1993.

4. Long JP, Anglard P, Gnarra JR, et al: The use of molecular genetic analysis in the diagnosis of renal cell carcinoma. World J Urol 12: 69-73, 1994 
5. Alimov A, Kost-Alimova M, Liu J, et al: Combined LOH/CGH analysis proves the existence of interstitial $3 p$ deletions in renal cell carcinoma. Oncogene 19: 1392-1399, 2000.

6. Martinez A, Fullwood P, Kondo K, et al: Role of chromosome 3p12-p21 tumour suppressor genes in clear cell renal carcinoma: analysis of VHL dependent and VHL independent pathways of tumorigenesis. Mol Pathol 53: 137-144, 2000.

7. Zbar B, Brauch H, Talmadge C and Linehan M: Loss of alleles of loci on the short arm of chromosome 3 in renal cell carcinoma. Nature 327: 721-724, 1987

8. Imai $\mathrm{K}$ and Yamamoto $\mathrm{H}$ : Carcinogenesis and microsatellite instability: the interrelationship between genetics and epigenetics. Carcinogenesis 29: 673-680, 2008.

9. Pedroni M, Sala E, Scarselli A, et al: Microsatellite instability and mismatch-repair protein expression in hereditary and sporadic colorectal carcinogenesis. Cancer Res 61: 896-899, 2001.

10. Thibodeau SN, French AJ, Roche PC, et al: Altered expression of hMSH2 and hMLH1 in tumors with microsatellite instability and genetic alterations in mismatch repair genes. Cancer Res 56: 4836-4840, 1996.

11. Shia J: Immunohistochemistry versus microsatellite instability testing for screening colorectal cancer patients at risk for hereditary nonpolyposis colorectal cancer syndrome. Part I. The utility of immunohistochemistry. J Mol Diagn 10: 293-300, 2008 .

12. Zhang L: Immunohistochemistry versus microsatellite instability testing for screening colorectal cancer patients at risk for hereditary nonpolyposis colorectal cancer syndrome. Part II. The utility of microsatellite instability testing. J Mol Diagn 10: 301-307, 2008.

13. Uchida T, Wada C, Wang C, Egawa S, Ohtani H and Koshiba K: Genomic instability of microsatellite repeats and mutations of $\mathrm{H}-, \mathrm{K}-$, and N-ras, and p53 genes in renal cell carcinoma. Cancer Res 54: 3682-3685, 1994.

14. Baiyee D and Banner B: Mismatch repair genes in renal cortical neoplams. Hum Pathol 37: 185-189, 2006.

15. Thrash-Bingham CA, Salazar H, Freed JJ, Greenberg RE and Tartof KD: Genomic alterations and instabilities in renal cell carcinomas and their relationship to tumor pathology. Cancer Res 55: 6189-6195, 1995.

16. Deguchi M, Shiina H, Igawa M, Kaneuchi M, Nakajima K and Dahiya R: DNA mismatch repair genes in renal cell carcinoma. J Urol 169: 2365-2371, 2003.

17. Rubio-Del-Campo A, Salinas-Sánchez AS, Sánchez-Sánchez F, et al: Implications of mismatch repair genes hMLH1 and hMSH2 in patients with sporadic renal cell carcinoma. BJU Int 102: 504-509, 2008

18. Perego RA, Corizzato M, Brambilla P, et al: Concentration and microsatellite status of plasma DNA for monitoring patients with renal carcinoma. Eur J Cancer 44: 1039-1047, 2008.

19. Nagy A, Buzogany I and Kovacs G: Microsatellite allelotyping differentiates chromophobe renal cell carcinomas from renal oncocytomas and identifies new genetics changes. Histopathology 44: 542-546, 2004.

20. Kok K, Draaijers TG, Mosselaar A, de Jong D and Buys CHCM: Inclusion of new microsatellite repeats in allelic loss analysis excludes retention of heterozygosity in the renal cell carcinoma critical region in 3p21. Cancer Genet Cytogenet 116: 40-43, 2000 .
21. Junker K, Thrum K, Schlichter A, Mueller G, Hindermann W and Schubert J: Clonal origin of multifocal renal cell carcinoma as determined by microsatellite analysis. J Urol 168: 2632-2636, 2002.

22. Jones TD, Eble JN, Wang M, et al: Molecular genetic evidence for the independent origin of multifocal papillary tumors in patients with papillary renal cell carcinomas. Clin Cancer Res 11: 7226-7233, 2005.

23. Leach FS, Koh M, Sharma K, et al: Mismatch repair gene mutations in renal cell carcinoma. Cancer Biol Ther 1: 530-536, 2002.

24. Kanomata N, Eble JN and Halling KC: Microsatellite instability is uncommon in young patients with renal cell carcinoma. Cancer Genet Cytogenet 101: 123-127, 1998.

25. Willers CP, Siebert R, Bardenheuer W, et al: Genetic instability of 3p12-p21-specific microsatellite sequences in renal cell carcinoma. Br J Urol 77: 524-529, 1996.

26. Diakoumis E, Sourvinos G, Kiaris H, Delakas D, Cranidis A and Spandidos DA: Genetic instability in renal cell carcinoma. Eur Urol 33: 227-232, 1998.

27. Hoefling C, Schmidt H, Meinhardt M, et al: Comparative evaluation of microsatellite marker, AP-PCR and CGH studies in primary renal cell carcinoma. Int J Mol Med 13: 835-842, 2004.

28. Salama ME, Worsham MJ and DePeralta-Venturina M: Malignant papillary renal tumors with extensive clear cell change. A molecular analysis by microsatellite analysis and fluorescence in situ hybridization. Arch Pathol Lab Med 127: 1176-1181, 2003.

29. Goessl C, Heicappell R, Muenker R, et al: Microsatellite analysis of plasma DNA from patients with clear cell renal carcinoma. Cancer Res 58: 4728-4732, 1998.

30. Girolami F, Passerini I, Gargano D, et al: Microsatellite analysis of chromosome $3 \mathrm{p}$ region in sporadic renal cell carcinomas. Pathol Oncol Res 8: 241-244, 2002.

31. Chen HC, Bhattacharyya N, Wang L, et al: Defective DNA repair genes in a primary culture of human renal cell carcinoma. J Cancer Res Clin Oncol 126: 185-190, 2000.

32. Ficarra V, Guille F, Schips L, et al: Proposal for revision of the TNM classification system for renal cell carcinoma. Cancer 104: 2116-2123, 2005.

33. Bocker T, Diermann J, Friedl W, et al: Microsatellite instability analysis: a multicenter study for reliability and quality control. Cancer Res 57: 4739-4743, 1997.

34. Marcus VA, Madlensky L, Gryfe R, et al: Immunohistochemistry for hMLH1 and hMSH2: a practical test for DNA mismatch repair-deficient tumors. Am J Surg Pathol 23: 1248-1255, 1999.

35. Chang DK, Ricciardiello L, Goel A, Chang CL and Boland CR: Steady-state regulation of the human DNA mismatch repair system. J Biol Chem 275: 18424-18431, 2000. 